\title{
Recombinant Lymphotoxin Beta
}

National Cancer Institute

\section{Source}

National Cancer Institute. Recombinant Lymphotoxin Beta. NCI Thesaurus. Code C1608.

Lymphotoxin is a cytokine that orchestrates lymphoid neogenesis and is present on the surface of activated T-, B-, and LAK cells as a heterotrimer of alpha and beta subunits. It is also secreted as an alpha homotrimer. LT beta glycoprotein is a $33 \mathrm{kD}$ type II membrane protein that anchors LT alpha to the cell surface. 